\title{
Safety of tiotropium
}

\author{
Indirect evidence suggests the Respimat inhaler is riskier than the Handihaler
}

\section{Christopher J Cates senior clinical research fellow}

St George's University of London, London, SW17 ORE, UK

Tiotropium is used to treat chronic obstructive pulmonary disease via two different inhaler devices: the original Handihaler (18 $\mu \mathrm{g}$ once daily), which uses a powder formulation, and the newer Respimat mist inhaler ( $5 \mu \mathrm{g}$ once daily). The two devices cannot be assumed to have the same safety profile, however, and the linked systematic review by Singh and colleagues (doi:10.1136/bmj.d3215) assessed all cause mortality in people with chronic obstructive pulmonary disease using the Respimat mist inhaler.

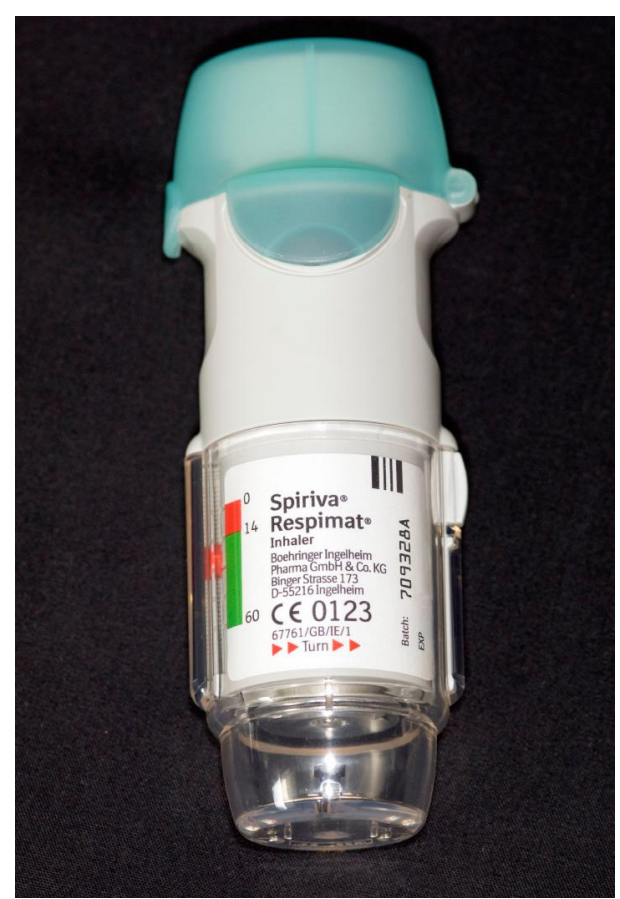

An ongoing trial will provide more certainty about the comparative safety of tiotroprium inhaler devices [Image: DR P. MARAZZISPL]

The authors assessed the risk of all doses of tiotropium given via the mist inhaler (including $10 \mu \mathrm{g}$ daily), but because the usual dose in clinical practice is $5 \mu \mathrm{g}$ daily, this editorial will focus on the safety results for this dose only. The review reported a $46 \%$ relative increase in risk of mortality from any cause in patients using the mist inhaler compared with placebo (relative risk $1.46,95 \%$ confidence interval 1.01 to 2.10 ).

Relative risks and odds ratios are used in meta-analyses because they tend to be more stable across trials of different durations and with participants at different baseline risks. However, it is misleading to describe the effect as a $46 \%$ increased risk of dying.

The impact of the relative risk depends on the baseline risk of the patient concerned. In this case, in trials that lasted for a year, 47 of 2655 participants taking placebo died, which gives a mortality risk of $1.8 \%$ a year. In the same trials, 68 of the 2659 participants taking $5 \mu \mathrm{g}$ of tiotropium via the mist inhaler died, which gives a mortality risk of $2.6 \%$ a year. The $46 \%$ relative increase in risk therefore represents an absolute difference of $0.8 \%$, because death was a rare event. The difference in absolute risk is shown in the Cates plot (www.nntonline.net/visualrx/ cates_plot/; figure), in which 18 deaths occurred in the trials for each 1000 patients treated for a year with placebo, and an extra eight occurred in those treated with tiotropium via the mist inhaler. This translates into an annual number needed to treat for one additional participant to suffer harm (NNT(H)) of 121 patients given $5 \mu \mathrm{g}$ tiotropium for a year for one additional death compared with patients given placebo. There is considerable uncertainty around this estimate, and the $95 \%$ confidence interval runs from anywhere between $\mathrm{NNT}(\mathrm{H})$ of 51 and 5556. However, this point estimate of the increased risk of mortality with the mist inhaler is considerably larger than that found for salmeterol in asthma (7/10 000 over 28 weeks). ${ }^{2}$ 


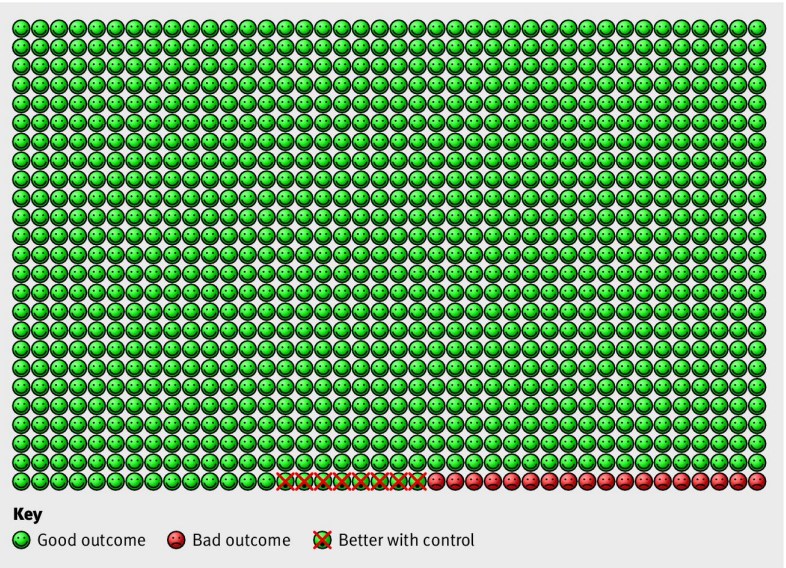

So how do we go about sharing this risk information with patients? What we really want to know is how the risk of the Respimat compares with that of the Handihaler. Although the UPLIFT trial did not report an increase in mortality in patients using the Handihaler, that trial differed greatly from those that looked at the Respimat, so differences between the delivery devices cannot be untangled from other differences between the trials. ${ }^{3}$ More certainty about the comparative safety of the two devices will have to wait for the results of the ongoing randomised trial mentioned by Singh and colleagues, ${ }^{4}$ which directly compares tiotropium delivered by the Handihaler (18 $\mu \mathrm{g}$ a day) or the Respimat ( $5 \mu \mathrm{g}$ and $2.5 \mu \mathrm{g}$ a day).

The improved delivery afforded by the mist inhaler could possibly increase plasma concentrations of tiotropium and therefore increase risks. Could the excess mortality in the Respimat trials be caused by the inclusion of patients who are taking $10 \mu \mathrm{g}$ a day? This is unlikely, because risk in patients taking the $5 \mu \mathrm{g}$ dose was still significantly increased. The Medicines and Healthcare Products Regulatory Agency currently advises caution when using the mist inhaler in patients with arrhythmias and that the recommended daily dose should not be exceeded. ${ }^{5}$
So where do we go from here? Pending the results of the head to head trial, the indirect evidence that is currently available suggests that the Handihaler is a safer bet than the Respimat. If patients have a strong preference for the mist inhaler, the possible increased risk in mortality will need to be shared with them, and the Cates plot might help to make this easier.

Competing interests: The author has completed the Unified Competing Interest form at www.icmje.org/coi_disclosure.pdf (available on request from the corresponding author) and declares: no support from any organisation for the submitted work; no financial relationships with any organisations that might have an interest in the submitted work in the previous three years; no other relationships or activities that could appear to have influenced the submitted work

Provenance and peer review: Commissioned; not externally peer reviewed.

1 Singh S, Loke YK, Enright PL, Furberg CD. Mortality associated with tiotropium mist inhaler in patients with chronic obstructive pulmonary disease: systematic review and inhaler in patients with chronic obstructive pulmonary disease: system
meta-analysis of randomised controlled trials. BMJ 2011;342:d3215.

2 Cates CJ, Cates MJ. Regular treatment with salmeterol for chronic asthma: serious adverse events. Cochrane Database Syst Rev 2008;3:CD006363.

3 Celli B, Decramer M, Kesten S, Liu D, Mehra S, Tashkin DP; UPLIFT Study Investigators. Mortality in the 4-year trial of tiotropium (UPLIFT) in patients with chronic obstructive pulmonary disease. Am J Respir Crit Care Med 2009;180:948-55

4 Comparison of tiotropium in the HandiHaler versus the Respimat in chronic obstructive pulmonary disease. NCT01126437. ClinicalTrials.gov http://clinicaltrials.gov/ct2/show/ NCT01126437.

5 Medicines and Healthcare Products Regulatory Agency. Tiotropium: safety studies of Spiriva Respimat. 2010. www.mhra.gov.uk/Safetyinformation/DrugSafetyUpdate/ CON099869.

Cite this as: BMJ 2011;342:d2970

\section{Related links \\ bmj.com/rapidreponse}

- "Obtaining a clinically significant difference in these trials is like winning an Olympic medal with statistical significance the equivalent of finishing fourth or fifth.” $\mathrm{R}$ Andrew McIvor, professor of medicine, McMaster University,Hamilton, Ontario, Canada 